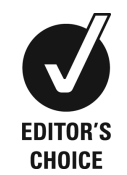

${ }^{1}$ Department of Oral Medicine \& Radiology, MES Dental College, Perinthalmanna, Kerala, India

${ }^{2}$ Department of Oral Pathology \& Microbiology, MES Dental

College, Perinthalmanna, Kerala, India

${ }^{3}$ Department of Paediatric dentistry, MES Dental College, Perinthalmanna, Kerala, India

\section{Correspondence to} Professor Abdul Hafiz, hafizzzdr@gmail.com

Accepted 15 February 2015

CrossMark

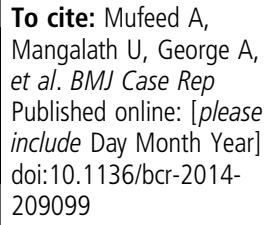

\title{
Infected florid osseous dysplasia: clinical and imaging follow-up
}

\author{
Abdulla Mufeed, ${ }^{1}$ Ummar Mangalath, ${ }^{1}$ Antony George, ${ }^{2}$ Abdul Hafiz $^{3}$
}

\section{SUMMARY}

Florid osseous dysplasia (FOD) is a rare fibro-osseous lesion of the jaw usually identified incidentally on radiograph. It rarely presents with clinical symptoms. A case of FOD presenting with features similar to osteomyelitis is discussed here. The diagnosis is based on radiographic findings; biopsy or surgical intervention should be avoided as it may predispose to infection.

\section{BACKGROUND}

Florid osseous dysplasia (FOD) refers to a group of fibro-osseous (cemental) exuberant lesions of the jaw with multi-quadrant involvement. It was previously known as sclerosing osteitis, multiple enostoses or gigantiform cementoma. The term florid cemento-osseous dysplasia was proposed in the second edition of the WHO International Histological Classification of Odontogenic Tumours to replace the term 'gigantiform cementoma'. ${ }^{1}$ However, WHO recommended the use of the term 'florid osseous dysplasia' as this condition is now generally accepted as a widespread, extensive form of cemento-osseous dysplasia. ${ }^{2}$

FOD is more common in middle-aged black females, with only rare cases reported from the Indian subcontinent. ${ }^{3}$ FOD is usually asymptomatic and diagnosed accidentally during routine dental radiographic examination. Symptoms such as dull pain, drainage, exposure of the lesion in the oral cavity, focal expansion and facial deformities may be seen when the lesion is infected.

\section{CASE PRESENTATION}

A 46-year-old female patient reported to the dental outpatient department with a 2-week history of swelling and discharge on the upper right side of her face (figure 1). The swelling was first noticed intra-orally and gradually increased in size. She did not recall any history of trauma and had not experienced any relevant systemic illness. The swelling involved the middle third of the right side of the face and was covered with a granulation-like tissue. On palpation, the swelling was non-tender, non-fluctuant and non-compressible. Intra-orally, considerable expansion of the labial and palatal cortex of the right maxilla was evident (figure 2) which was bony hard and non-tender. Teeth 25 and 26 had deep caries occlusally, and minimal expansion of the maxillary alveolus was also evident on the left side. Clinically, a differential diagnosis of fibro-osseous lesions, ossifying fibroma and chronic osteomyelitis was considered.

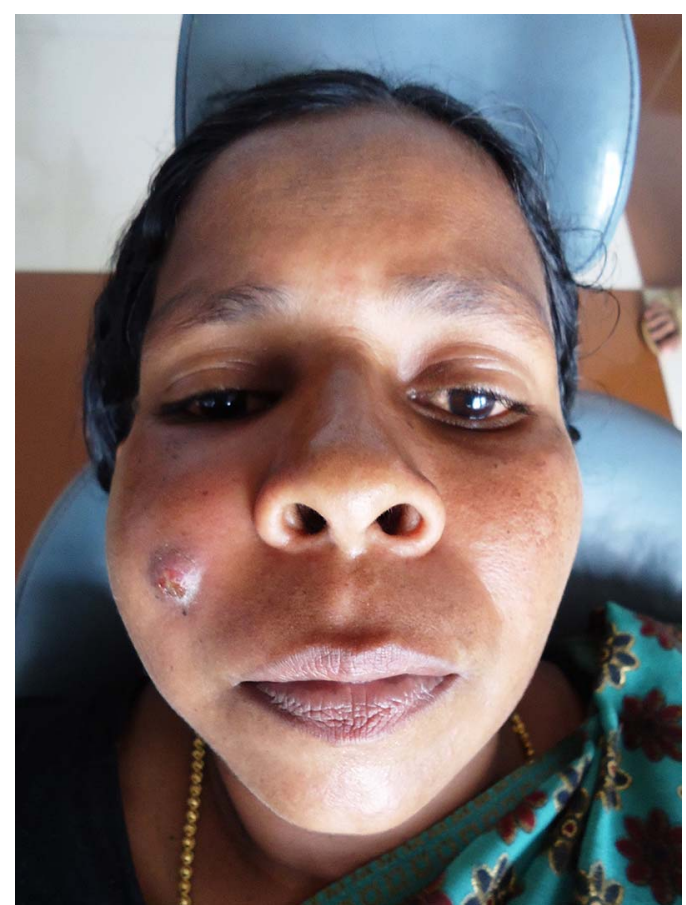

Figure 1 Swelling and discharge on the right maxilla.

\section{INVESTIGATIONS}

A maxillary occlusal radiograph was taken which showed a diffuse periapical radiopacity in the premolar/molar region with expansion of the buccal cortex. CT showed the presence of an expansile lobulated lesion involving the posterior part of the

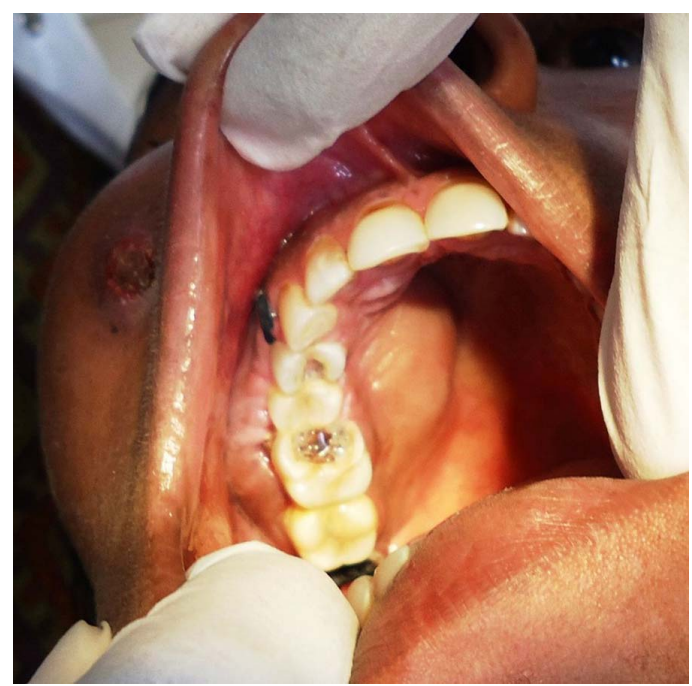

Figure 2 Bucco-lingual expansile swelling. 


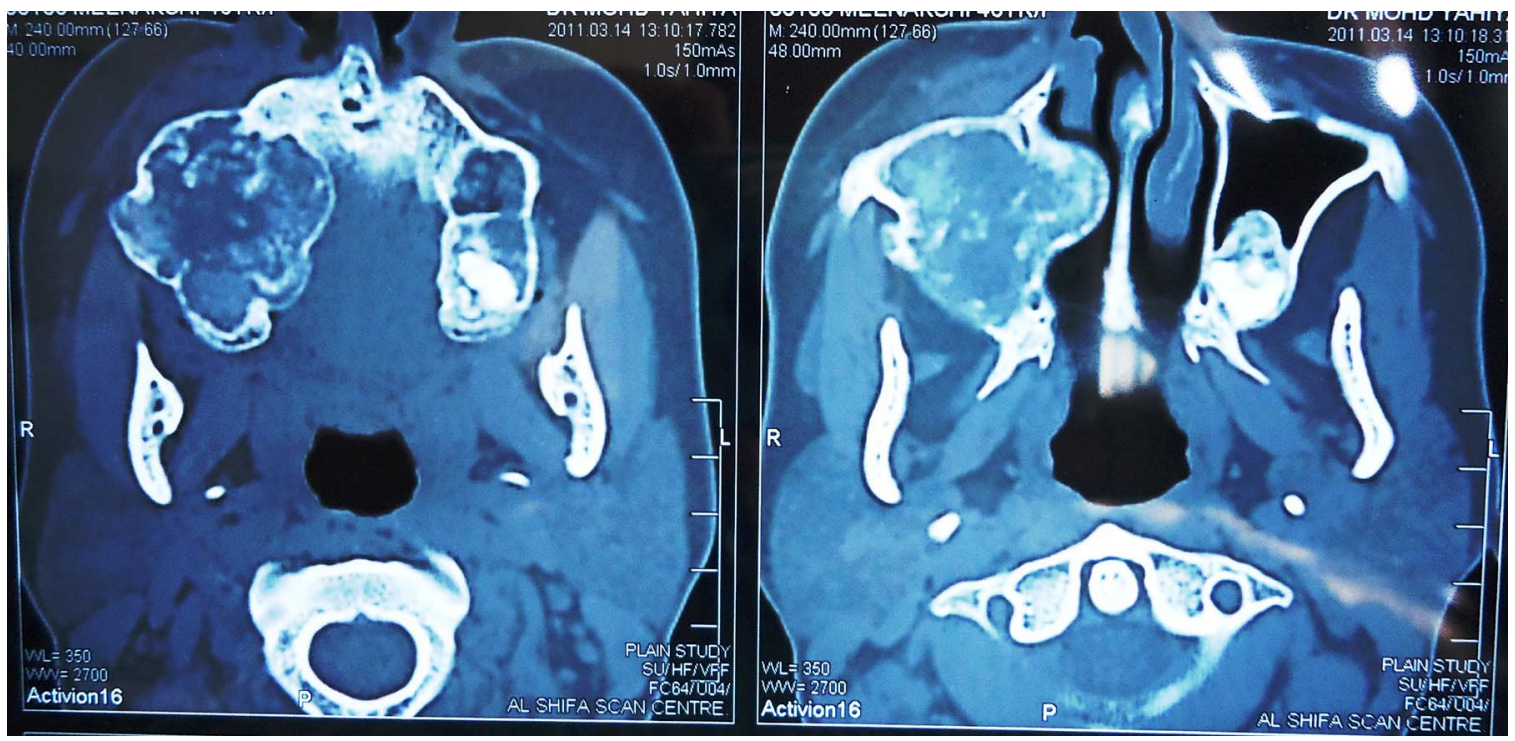

Figure 3 Coronal CT demonstrating an expansile lobulated lesion of the right maxillary alveolar ridge with invasion into the maxillary sinus and nasal cavity.

right maxillary alveolar ridge and measuring $4.6 \mathrm{~cm} \times 3.8 \mathrm{~cm}$ with invasion superiorly into the maxillary sinus and laterally into the right nasal cavity (figure 3). Similar lesions were also noticed symmetrically on the left posterior maxilla together with a small area of increased density in the left mandibular periapical area. Based on the imaging findings of the multifocal presentation, the possibility of FOD was considered.

\section{DIFFERENTIAL DIAGNOSIS}

In light of the clinical and imaging findings, chronic diffuse osteomyelitis, fibrous dysplasia, Gardner's syndrome and Paget's disease were also included on the differential diagnosis list.

\section{TREATMENT}

Under local anaesthesia, a crevicular incision was placed on the buccal vestibular region of the right maxillary posterior region, the necrotic area of the lesion was exposed and surgical curettage was performed. Irregular bony defects and inflammatory fibrous tissue were seen in the operation field. The grossly

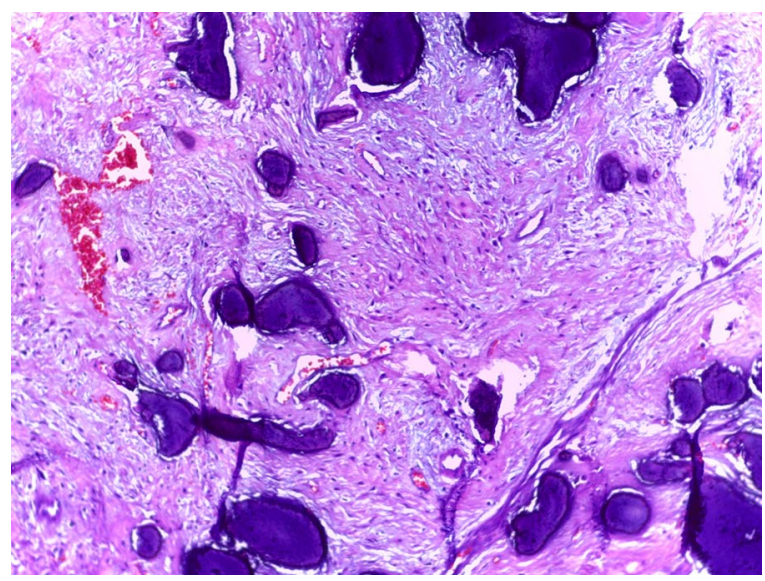

Figure 4 Histological photograph showing a myxomatous connective tissue with coarse woven bone spicules and areas of irregularly shaped calcified masses. decayed premolars and first molar tooth were also extracted at the same time.

The surgical specimen submitted for histopathological examination felt gritty during gross examination. The examined section showed a myxomatous fibrovascular connective tissue having numerous coarse woven bone spicules with a few showing osteoblast and multinucleated osteoclast rimming, focal areas of irregularly shaped calcified masses with some showing retraction from adjacent stroma, focal areas of cellular giant cell fibroblasts, and areas of extravasated red blood cells (figure 4). The histopathological features correlated with the features of FOD.

\section{OUTCOME AND FOLLOW-UP}

The patient was recalled after 2 weeks. An oro-antral communication was seen on examination (figure 5), so an impression was made for an obturator which was delivered after 5 days and fitted. The patient was recalled again after 6 months to assess the prognosis and to evaluate her quality of life. She had intermittent pain and occasional discomfort, probably due to the illfitting obturator after tissue remodelling. The obturator was replaced and she is currently doing well. A panoramic radiograph was obtained for review which showed the presence of

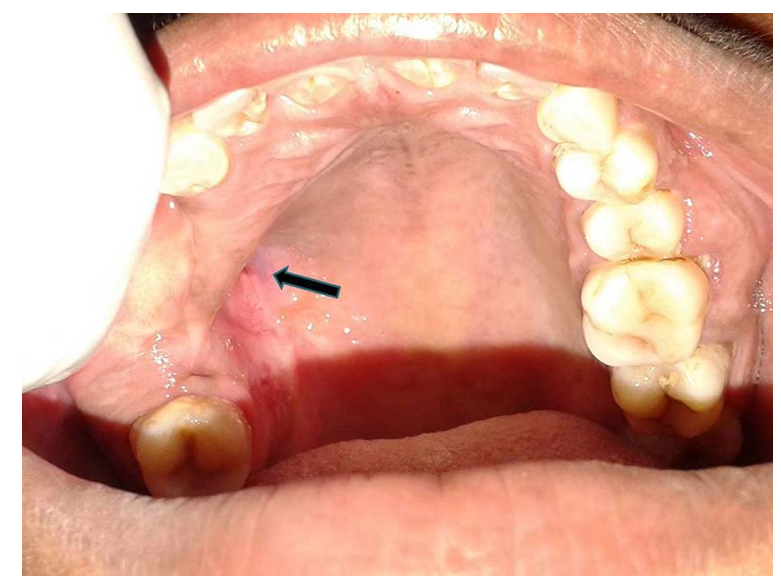

Figure 5 Oro-antral communication. 


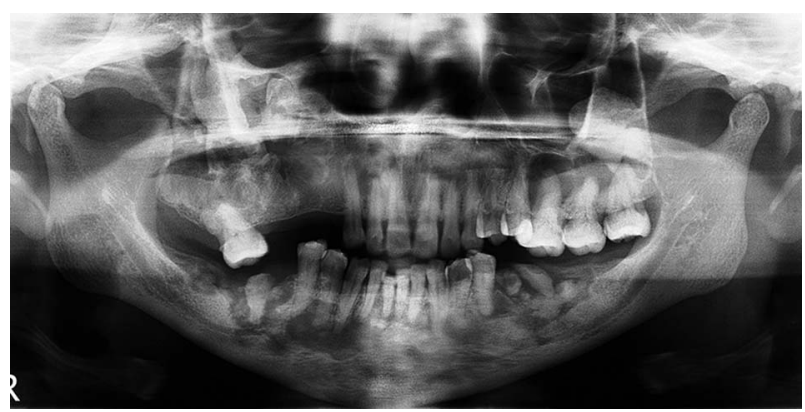

Figure 6 Follow-up radiograph demonstrating multiple periapical radiopaque areas.

irregular radiopacity at the surgical site. Multifocal radiopacities were also seen in the left maxilla as well as the mandibular anterior and bilateral posterior regions that were bounded by irregular radiolucencies (figure 6). These findings further established the diagnosis of FOD and the patient was discharged with assurance and instructions.

\section{DISCUSSION}

WHO classified bone-related lesions and non-neoplastic fibro-osseous lesions as FOD in 2005. Based on the location of the lesion, osseous dysplasia has been classified into four groups: periapical osseous dysplasia (POD), focal osseous dysplasia, FOD and familial gigantiform cementoma. ${ }^{2}$ POD is found at the apices of the anterior teeth and usually does not grow beyond $1 \mathrm{~cm}$, while focal osseous dysplasia is usually seen at two or more mandibular anterior teeth or at the apices of molar teeth, and rarely grow more than $2 \mathrm{~cm}$. On the other hand, FOD appears bilaterally and is often quite symmetrical. The term 'florid' refers to its excessive and widespread manifestation. ${ }^{45}$

FOD has three developmental stages, all of which have a different radiographic appearance. The first or osteolytic stage is seen as a well-defined radiolucent area with loss of lamina dura and periodontal ligament. In the second or cementoblastic stage, due to deposition of cementum-like precipitations in the fibrous tissue, small radiopacities appear in the radiolucent area. The last stage, when most cases are identified, is characterised as definite radiopacity. In the present case, the maxillary lesions appeared to be in the late radiopaque stage, while the mandibular lesions were in the early to second stage. Diagnosis is made by clinical and radiographic examination. As the clinical and radiographic findings are characteristic, biopsy is better avoided because of the risk of infection, sequestrum formation and osteomyelitis. ${ }^{6}$ Extraction or excision of the lesion is not recommended for the same reasons. We decided on extraction as the decayed teeth could not be restored and could be the source of infection. For asymptomatic patients, such treatment is not necessary and first-line treatment is routine follow-up and protection from infection. Treatment options for symptomatic patients are antibiotic therapy and sequestrectomy. ${ }^{7}$ Another possible complication is difficult-to-control infection due to insufficient antibiotic concentration in the lesion area owing to reduced blood flow. In our case, since the patient presented with discharge and other features of infection, surgical curettage was carried out under antibiotic coverage.

The differential diagnosis of FOD should include Paget's disease of bone, chronic diffuse osteomyelitis and Gardner's syndrome. The skin tumours, dental anomalies and skeletal changes associated with Gardner's syndrome are not seen in FOD. In Paget's disease of bone, there is no radiolucent capsule around the radiopaque masses, and it is also usually polyostotic and causes a raised alkaline phosphatase level. Chronic diffuse osteomyelitis is not limited to tooth-bearing areas and causes unilateral pain and swelling. In our case, serum alkaline phosphatase levels were within the normal range and the patient had neither dental anomalies nor skin tumours.

\section{Learning points}

- Florid osseous dysplasia (FOD) should be considered when multiple diffuse radiopaque jaw lesions are identified on radiographs.

- The clinical and radiographic findings confirm the diagnosis of FOD, which does not require treatment.

- Surgical resection and biopsy are better avoided in FOD to avoid infections and complications.

- The role of the dentist is to ensure patients are followed up and measures are taken to prevent infection.

Competing interests None.

Patient consent Obtained.

Provenance and peer review Not commissioned; externally peer reviewed.

\section{REFERENCES}

1 Pindborg JJ, Kramer IRH, Torloni H. Histological typing of odontogenic tumours, jaws cysts and allied lesions. Geneva, Switzerland: WHO, 1971.

2 Barnes L, Eveson JW, Reichart P, et al. Pathology and genetics of head and neck tumours. World Health Organization Classification of tumours. Lyon: IARC Press, 2005:323.

3 Melrose RJ, Abrams AM, Mills BG. Florid osseous dysplasia: a clinico-pathologic study of 34 cases. Oral Surg Oral Med Oral Path 1976;41:62-82.

4 Mangala M, Ramesh DN, Surekha PS, et al. Florid cemento-osseous dysplasia Review and report of two cases. Indian J Dent Res 2006;17:131-4.

5 Sarmento DJ, Monteiro BV, de Medeiros AM, et al. Severe florid cemento-osseous dysplasia: a case report treated conservatively and literature review. Oral Maxillofac Surg 2013;17:43-6.

6 Sanjai K, Kumarswamy J, Kumar VK, et al. Florid cemento osseous dysplasia in association with dentigerous cyst. J Oral Maxillofac Pathol 2010;14:63-8.

7 Neville BW, Damm DD, Allen CM, et al, eds. Bone pathology. In: Oral and maxillofacial pathology. St. Louis, Missouri: Saunders Elsevier, 2009. 
Copyright 2015 BMJ Publishing Group. All rights reserved. For permission to reuse any of this content visit http://group.bmj.com/group/rights-licensing/permissions.

BMJ Case Report Fellows may re-use this article for personal use and teaching without any further permission.

Become a Fellow of BMJ Case Reports today and you can:

- Submit as many cases as you like

- Enjoy fast sympathetic peer review and rapid publication of accepted articles

- Access all the published articles

- Re-use any of the published material for personal use and teaching without further permission

For information on Institutional Fellowships contact consortiasales@bmjgroup.com

Visit casereports.bmj.com for more articles like this and to become a Fellow 